\title{
Interaction of the Oncofetal Thomsen-Friedenreich Antigen with Galectins in Cancer Progression and Metastasis
}

\author{
Paulina Sindrewicz ${ }^{1}$, Lu-Yun Lian ${ }^{2}$ and Lu-Gang Yu ${ }^{1 *}$ \\ ${ }^{1}$ Gastroenterology Unit, Department of Cellular and Molecular Physiology, Institute of Translational Medicine, University of \\ Liverpool, Liverpool, UK, ${ }^{2}$ NMR Centre for Structural Biology, Institute of Integrative Biology, University of Liverpool, \\ Liverpool, UK
}

Aberrant glycosylation of cell membrane proteins is a universal feature of cancer cells. One of the most common glycosylation changes in epithelial cancer is the increased occurrence of the oncofetal Thomsen-Friedenreich disaccharide Galp1-3GalNAc (T or TF antigen), which appears in about $90 \%$ of cancers but is rarely seen in normal epithelium. Over the past few years, increasing evidence has revealed that the increased appearance of TF antigen on cancer cell surface plays an active role in promoting cancer progression and metastasis by interaction with the $\beta$-galactoside-binding proteins, galectins, which themselves are also frequently overexpressed in cancer and pre-cancerous conditions. This review summarizes the current understanding of the molecular mechanism of the increased TF occurrence in cancer, the structural nature, and biological impact of TF interaction with galectins, in particular galectin-1 and -3 , on cancer progression and metastasis.

Keywords: galectin, TF antigen, metastasis

\section{INTRODUCTION}

Glycosylation is one of the most common post-translational modifications of cell membrane proteins (1). Among the two major types of protein glycosylation in human cells, the N-linked glycosylation is characterized by attachment of carbohydrates to the amide group of asparagine residues of proteins in the consensus sequence Asn-X-Ser/Thr, whereas in the classical O-linked mucin-type glycosylation, $\mathrm{N}$-acetyl-galactosamine is covalently linked to the hydroxyl group of serine or threonine residue of the protein backbone $(2,3)$. O-linked protein glycosylation occurs during protein movement through ER-Golgi pathway by sequential incorporation of monosaccharides; this process is controlled by various factors, such as relative abundances of glycosyltransferases and glycoprotein substrates, as well as the availability of sugar-donor molecule $(2,3)$. Altered glycosylation of cell membrane proteins is a hallmark of cancer and a universal feature of oncogenesis and cancer progression $(2,4)$. Such glycosylation changes typically include the occurrence of incomplete or truncated glycan structures, accumulation of glycan precursors, or the presence of novel tumorspecific carbohydrate epitopes. More and more evidence shows that these glycosylation changes on cancer cell surface are critically involved in the regulation of cell social behaviors and is increasingly recognized to play an important role in cancer development, progression, and metastasis (2). One of the most prevalent glycosylation alterations in human carcinomas is the increased occurrence 
of short carbohydrate structure Gal $\beta 1-3 \mathrm{GalNAc} \alpha$, also known as the oncofetal Thomsen-Friedenreich (TF or T) antigen. The TF antigen is the core I structure of $O$-linked mucin-type glycans. In normal epithelium, TF structure is masked by other sugar residues to form branched and complex glycans or being modified by sialidation, sulfation, or fucosylation $(5,6)$. Low level of TF expression was occasionally reported in normal epithelium (7), but this was suspected to be related to the use of less/different specific analytic tools in the studies. Peanut agglutinin, one of the most commonly used analytic tools to detect TF expression in tissue sections, is known to also recognize other sugar structures (although with low affinity) such as terminal galactose and Gal $\beta 1 \rightarrow 4$ GlcNAc (8). Different anti-TF antibodies also show to bind TF-related structures differently (9). Un-masked and unsubstituted TF structure is known to occur in about $90 \%$ of all cancers (5). There is a considerable amount of literature showing a positive correlation between the occurrence of TF and tumor progression in various types of cancer (10-12).

\section{MOLECULAR MECHANISMS LEADING TO INCREASED TF OCCURRENCE IN CANCER}

Despite unequivocal evidence of the widespread appearance of TF in cancer cells, the exact mechanisms underlying this increased TF availability in cancer is not fully understood. Biosynthesis of the mucin-type $O$-linked glycans occurs by transferation of individual carbohydrate moieties from nucleotide sugar donor molecules to the acceptor in a stepwise manner in the Golgi apparatus $(6,13)$. TF antigen is an intermediate structure in the biosynthesis of complex $O$-linked oligosaccharides. Its formation is carried out by the addition of galactose (Gal) from UDP-Gal to the precursor structure GalNAc (Tn antigen) by core $1 \beta 1,3$ galactosyltransferase, also known as $\mathrm{T}$ synthase $(13,14)$. It is believed that unbalanced expression of glycosyltransferases involved in the glycosylation pathways, such as T synthase, $\beta 1,6$ GlcNAc-transferase, sulfotransferase, and sialyltransferases, as well as altered availability of precursor monosaccharide molecules, is responsible for altered glycosylation patterns in cancer and thus are probably the main factors responsible for enhanced availability of TF disaccharide (15-19). In addition, changes in acidification of Golgi apparatus have been shown to correlate to enhanced TF expression in breast and colorectal cancer cells (20). Furthermore, the availability and activity of molecular chaperone Cosmc, which is required for proper folding of a functional $\mathrm{T}$ synthase (21), also influences the overall TF appearance in cancer. Mutations of Cosmc in human colon carcinoma LSC cells have been shown to account for the reduced $\mathrm{T}$ synthase activity and enhanced occurrence of Tn and sialyl-Tn antigens (22). Cosmc knockdown in pancreatic cells was seen to lead to aberrant O-glycosylation and acquisition of oncogenic properties (23). Forced expression of Cosmc in HCT116 colon cancer cells resulted in enhanced TF expression and increased cell growth, migration, and invasion (24). It should be noted, however, that in breast cancer cells, TF antigen was seen to be still expressed along with Tn and sialyl-Tn antigens in the absence of Cosmc, suggesting that the chaperone function of Cosmc is not a sole determinant in the enhanced expression of TF in those cells (14).

\section{TF ANTIGEN-EXPRESSING PROTEINS IN CANCER}

A number of proteins are known to carry the unsubstituted TF structure in cancer. These include the adhesion molecules CD34 and CD44 $(25,26)$ and the transmembrane mucin proteins MUC1 and MUC4 $(5,27,28)$. Interestingly, CD34 and CD44 are also known as cancer stem cell markers, which are unique for specific types of cancer, for example, CD34 in leukemia and sarcoma, whereas CD44 in colon and breast cancer $(5,29)$. CD34, identified as hematopoietic cell surface antigen, is a transmembrane protein involved in cell adhesion and homing of leukocytes to the endothelium during inflammatory responses (30), whereas CD44 is a major hyaluronan receptor that is involved in hematopoietic stem cell and leukemia-initiating cell homing and migration (31). The TF-bearing protein MUC1 is a large and heavily glycosylated transmembrane mucin protein that is overexpressed by most cancer cells of epithelial origin $(2,32)$. Cancer-associated MUC1 also carries other truncated oligosaccharides such as Tn and sialyl-Tn antigens (33). In contrast to its polarized localization on the apical surface of epithelial cells in normal epithelium, cancer-associated MUC1 loses its apical localization and is expressed on the entire cell surface $(2,34)$.

Over the past decade, more and more evidence has revealed that the pan-carcinoma-associated TF antigen is a natural ligand of the galactoside-binding galectins and the TF-galectin interaction influences a number of key steps in cancer progression and metastasis.

\section{GALECTINS}

Galectins are a family of 15 (so far) mammalian $\beta$-galactosidebinding proteins. Each galectin member contains one or two well conserved carbohydrate recognition domains (CRDs) that recognize galactose-terminated glycans $(35,36)$. Galectins are widely expressed by human cells and are divided into three subgroups of proto-type, tandem repeat type, and chimera type based on their structural differences. The prototype galectins include galectin-1, -2, -5, -7, -10,-11,-13,-14, and -15 , each with one CRD. The tandem repeat type galectins include galectin $-4,-6,-8$, -9 , and -12 , each contains two CRD connected by a short linker region. Galectin-3, the only chimera type galectin, consists of one CRD at its C-terminus and an extended and flexible $\mathrm{N}$-terminal $(35,37)$. The N-terminal domain of galectin-3, which is often referred to as collagen-like domain, is responsible for galectin-3 multimerization upon galectin-3 contact with multivalent ligands $(38,39)$. Despite sharing conserved CRDs, galectins often display significant differences in their binding specificities to branched, repeated, or modified galactose residue $(40,41)$. These binding differences of galectin members toward oligosaccharides are believed to have implications in their biological activities in physiological and pathological conditions (41).

A number of galectins show altered expression, very often increased expression, in tumor cells compared with their normal 
counterparts. In many cases, the altered expression of galectins correlates to the acquisition of aggressive and metastatic phenotype $(42,43)$. There is a large body of evidence showing that galectins play important roles in tumor transformation, cancer cell adhesion, invasion, migration, and angiogenesis through multiple mechanisms (44). These divergent actions of galectins are partly derived from the ability of galectins to interact with various galactose-terminated glycans in different environments.

\section{INTERACTION OF CANCER-ASSOCIATED TF WITH CANCER- AND ENDOTHELIAL-ASSOCIATED GALECTINS IN CANCER PROGRESSION AND METASTASIS}

In 2000, Glinsky and colleagues first reported an interaction of TF with galectin-1 and -3 in cell-cell homotypic aggregation and cell adhesion to cultured human vascular endothelial cells of human breast and prostate cancer cells. They showed that these galectin-mediated cell-cell interactions were inhibited by the presence of TF-binding peptide P-30, TF-antigen mimicking compound lactulosyl-L-leucine, or anti-TF monoclonal antibody (45-47). Interaction of cancer-associated TF with endotheliumassociated galectin-3 showed to affect initial stages of cancer cell-endothelium adhesion (45-47). Several other investigations subsequently also reported a role of galectin-3-TF interaction in mediating cancer cell adhesion to the endothelium in vitro and in mice (48-50). Inhibition of the galectin-TF interaction by antiTF antibody, anti-galectin-3 antibody, modified citrus pectin, or lactulosyl-L-leucine suppressed the adhesion of human breast carcinoma cells to HUVECs and endothelial bone marrow cells 60 (HBMECs-60) in vitro and in ex vivo perfused porcine dura mater model (48).

Cancer cell-endothelial interaction mediated by cancer cellassociated TF was also shown to enhance expression of endothelial cell surface-associated galectin-3, resulting in increased adhesion of breast and prostate cancer cells to the endothelium of intact well-differentiated micro-vessels (51). The same phenomenon of galectin-3 cell surface mobilization in endothelial cells was noticed in cell response to the highly metastatic, TF antigenexpressing MDA-MB-435 cells but not in TF antigen-deficient MDA-MB-468 cells (45). These discoveries suggest that cancer cell-associated TF serves not only as a ligand for endotheliaassociated galectin-3 in cell adhesion but also as an activator for endothelial translocation of intracellular galectin-3 to the cell surface, where it may prime the endothelium for subsequent binding/docking of circulating tumor cells in metastasis (45).

\section{INTERACTION OF CANCER-ASSOCIATED TF ANTIGEN WITH CIRCULATING GALECTINS IN METASTASIS}

Over expression of MUC1 as well as increased occurrence of TF antigen carried by MUC1 are both characteristic features of epithelial cancer cells. Increased levels of circulating galectin members, in particular galectin-3, are also commonly seen in cancer patients (52). Patients with metastasis are seen to have higher galectin-3 serum concentration than those with localized tumors (52). Studies over the past 10 years have shown that the increased levels of galectins in the bloodstream, in particular galectin-3, may play an important role in promoting circulating tumor cells hematogenous dissemination to remote tumor sites as a result of their increased interactions with TF presented by MUC1 on the surface of tumor cells. Interaction of galectin-3 with TF on cancer-associated MUC1 causes MUC1 cell surface polarization, resulting in exposure of the underlying smaller adhesion molecules, which are otherwise masked by the large size of MUC1 (53). This showed to lead to increased adhesion of disseminating tumor cells to the blood vascular endothelium (54). Changes of MUC1 cell surface localization in response to galectin-3 binding also induce cancer cell homotypic aggregation and the formation of circulating tumor emboli, thus preventing the cells from undergoing anoikis and prolonging the cell survival (55). It was found that a tiny $3 \%$ tumor cell clusters in the total circulating tumor cells could account for strikingly over $50 \%$ of the metastasis in a mouse metastasis model, and that the continued presence of even $5 \%$ tumor cell clusters in the blood was correlated significantly to reduced overall survival in breast and prostate cancer patients (56). Interaction of galectin- 3 with the TF on the mucin protein MUC4 was also reported to produce a similarly enhanced cell adhesion of pancreatic cancer cells (27). Although with different binding affinities, other galectin members also recognize TF antigen and several of them, such as galectin-1, galectin-2, -4 , and -8 , are shown to also have elevated levels in the circulation of cancer patients (57). It is possible that, like galectin-3, the increased interactions of these galectin members with cancer-associated TF/MUC1/4 in circulation may also influence tumor cell metastatic spread. In support of this, exogenous introduction of recombinant galectin-2, -4 , or -8 at broadly pathological concentrations observed in cancer showed to induce changes of MUC1 cell surface localization and increase of cancer cell adhesion to endothelial monolayers in cell culture (57). The reported actions of TF-galectin interaction on cancer cell behaviors in cancer progression and metastasis are summarized in Table $\mathbf{1 .}$

The influence of TF-galectin interaction on cancer progression and metastasis raises the possibility that therapeutic inhibition of such interactions may be a viable strategy to reduce

TABLE 1 | Influences of TF-galectin interaction on cancer cell behaviors in cancer progression and metastasis.

\begin{tabular}{llc}
\hline & Consequences of TF-galectin interaction & Reference \\
\hline Galectin-1 & Increased cancer cell-cell homotypic aggregation & $(47)$ \\
& Increased cancer cell-endothelial adhesion & $(47)$ \\
Galectin-2 & Increased cancer cell-endothelial adhesion & $(57)$ \\
Galectin-3 & Changes of MUC1 cell surface polarization & $(54)$ \\
& Increased cell-cell homotypic aggregation & $(46,47,55)$ \\
& Increased cancer cell-endothelial adhesion & $(27,45-47,53)$ \\
Galectin-4 & Increased cancer cell-endothelial adhesion & $(55)$ \\
Galectin-8 & Increased cancer cell-endothelial adhesion & $(57)$
\end{tabular}


cancer progression and metastasis. Several possibilities are currently being explored by a few laboratories. These include the use of anti-TF antibodies, TF-mimicking peptides (49), negative galectin-3 mutants (58), and synthetic (59) and semi-synthetic oligosaccharides (60), and several approaches have shown promise in animal models and are currently undergoing clinical trials.

\section{THE STRUCTURAL NATURE OF TF-GALECTIN INTERACTION}

All galectins contain at least one CRD, which is responsible for their binding to galactose-terminated glycans. This conserved sequence, consisting of approximately 130 amino acid residues, adopts a typical $\beta$-sandwich motif formed by six-stranded and five-stranded antiparallel $\beta$-sheets. The carbohydrate-binding site of galectins is localized within $\beta$-strands $1-6$ of the concave surface $(35,61-63)$. Although all galectins share this CRD with well-conserved three-dimensional structure, the quaternary structures of galectins differ and are believed to influence their biological activities $(35,64)$. Studies using fungal galectin CGL2 from Coprinopsis cinerea, mouse galectin-9 N-terminal CRD, and mushroom Agrocybe aegerita galectin AAL provided structural insight into the recognition specificity and binding mechanisms between TF disaccharide and galectins $(37,65,66)$. Not surprisingly, the galactose moiety of TF disaccharide was found to orientate and interact in the same manner as lactose $/ N$ acetyl-lactosamine-derived structures. The GalNAc moiety of the TF antigen is involved in TF interactions with fungal galectin CGL2 and mouse galectin-9 via formation of hydrogen bonds with Arg and Glu residues within their binding sites $(37,65)$. In contrast, studies using mushroom $A$. aegerita galectin AAL revealed specific Arg-water-Glu-water structural motif-based hydrogen bonding network that was unique for galectin-TF antigen association (66).
Among human galectins, galectin-1 and -3 gained most attention due to their cancer-related activities. The nature of TF interaction with human galectin-1 and -3 were first reported by Bian and co-workers (63). Their studies revealed differences in binding of the two galectins to TF disaccharides that were attributed to subtle difference in their CRD sequences. Isothermal titration calorimetry analysis showed that the galectin-3-TF interaction $(\mathrm{Kd}=47 \mu \mathrm{M})$ is two orders of magnitude stronger than galectin1 - TF interaction $(\mathrm{Kd}=4 \mathrm{mM})$. The galectin- 3 residues engaged in its interaction with TF occur on strands $4-6$ of the concave $\beta$-sheet and the loop linking strands 4 and 5 (Figure 1). Currently, there is no experimentally determined galectin-1 complex with TF disaccharide; a recent study has reported galetin-1 in complex with Gal $\beta 1-3 / 4$ GINAc (67). Interestingly, detailed analysis of galectin-3 interaction with TF, particularly with the GalNAc moiety, brought to light the importance of hydrogen bond network, previously observed in mushroom galectin AAL. This Arg186-water1-Glu165-water2 structural motif-based hydrogen bond network was suggested to play a role as a major determinant for specific TF recognition and high affinity binding of galectin-3. Importantly, this unique recognition mode was also found in galectin-3 complexes with two TF antigen derivatives, TFN and GM1. The most restricting factor for TF binding to galectin- 1 was found to be a pentad residue motif ${ }^{51} \mathrm{AHGDA}^{55}$ at the loop 4 linking $\beta$-strands 4 and 5 , which was shown to force the loop to adopt different conformation from loop 4 in galectin-3. In addition, the His residue within the galectin- 1 sequence exerts a serious steric hindrance for the carbohydrate binding. Mutagenesis experiments confirmed the pentad residue sequence within galectin-1 loop 4 to be the major factor influencing the difference between bindings of galectin-1 and galectin-3 to TF structure (63).

The TF disaccharide is linked to its carrier proteins via serine or threonine residues in glycans. Galectin interaction with TF has been reported to include galectin interaction with the TF-protein backbone, which additionally enhances the binding
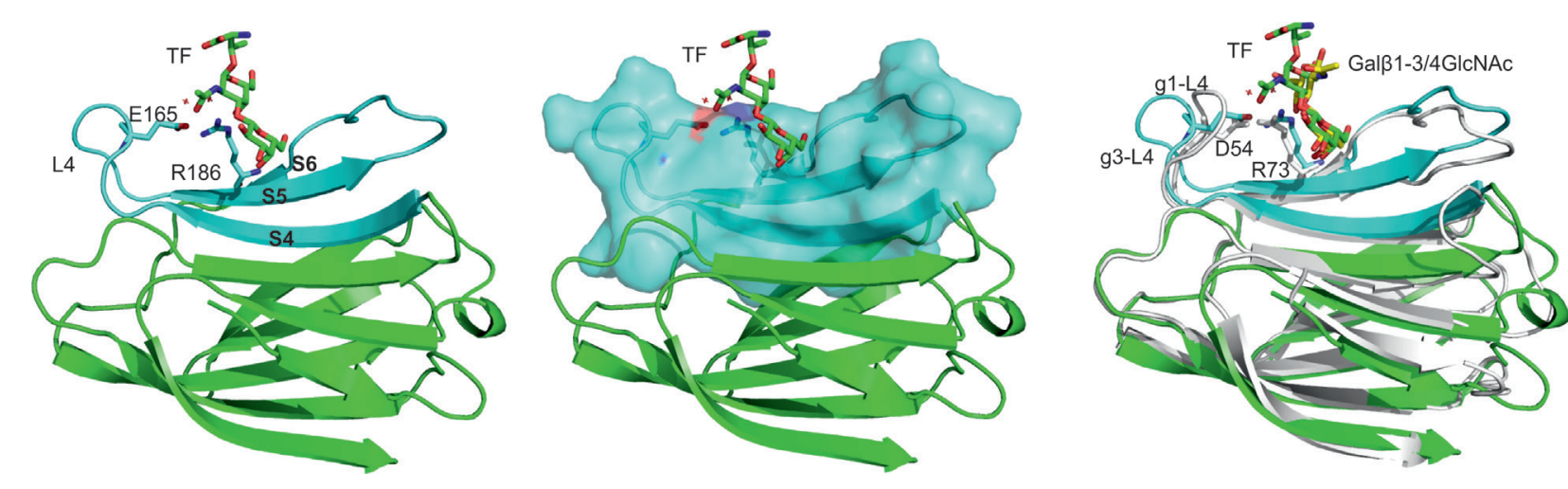

FIGURE 1 | Structural feature of galectin-3-TF interaction. Left panel: overall structure of galectin-3 CRD in complex with TF disaccharide (PDB 3AYA) (63). TF disaccharide (in stick model) binds to the CRD concave surf forms a $\mathrm{E}^{165}$-water-R ${ }^{186}$-water motif for TF recognition. Residues from strands S4-S6 (colored cyan) interact with the TF; L4 is the loop between S4 and S5. Middle panel: surface representation of strands S4-S6. Left panel: comparison between the structures of galectin-3 complex with the TF disaccharide and galectin-1 complex with Gal/11-3/4GlcNAc disaccharide (PDB 4XB1) (76). Galectin-3/TF is in green; galectin-1/ Galß1-3/4GlcNAc in white cartoon/yellow sticks. g1-L4 and g3-L4 are, respectively, the L4 loop for galectin-1 and galectin-3, which are found to adopt different conformations due to differences in the lengths and amino acid sequences of the two loops. D54 and R73 make up D ${ }^{54}$-water-R ${ }^{73}$-water motif that mediates ligand interactions. 
(68-70). Structural analysis on binding of avian galectin-3 to TF-threonine conjugate shows transient interaction between galectin-3 and amino acid threonine (71). Kinetic analysis reveals that the linkage of TF disaccharide to MUC1 fragments influenced the thermodynamic binding profile of galectin-3. The binding affinity of galectin-3 to TF-carrying glycans showed to be more than fivefold higher than to free TF disaccharide (72). These discoveries are in line with previous observations of other carbohydrate-binding proteins showing that lectin binding to glycoconjugates tends to be stronger than binding to carbohydrates (73). It should be stressed that all the information obtained so far for the TF-galectin-3 interaction were conducted using the CRD domain of galectin-3 and no information is yet available for full-length galectin-3. As the protein backbone of TF-expressing proteins is actively involved in galectin binding to TF-expressing glycans, future studies with full-length galectin-3 will be paramount to understand the exact mechanisms of the TF-galectin-3 interaction at molecular and submolecular levels.

Another feature of the galectin-TF interaction is protein multimerization. Cross-linking of multivalent glycoconjugates and receptors can lead to increase in galectin binding affinity. This phenomenon is known to play an important role in providing the required affinity and specificity of galectin actions (74). Isothermal titration micro-calorimetry analysis of galectin binding to multivalent carbohydrates by Dam et al. suggested that galectin-induced glycan clustering could enhance subsequent binding events by as much as 10,000-fold (75). So, even though galectin binding to certain glycans shows low affinity in vitro, their interactions in physiological and pathological conditions may be much stronger and hence functionally significant.

\section{REFERENCES}

1. Stillwell W. An Introduction to Biological Membranes: From Bilayers to Rafts. London: Elsevier Science (2013).

2. Tuccillo FM, de Laurentiis A, Palmieri C, Fiume G, Bonelli P, Borrelli A, et al. Aberrant glycosylation as biomarker for cancer: focus on CD43. Biomed Res Int (2014) 2014:742831. doi:10.1155/2014/742831

3. Moremen KW, Tiemeyer M, Nairn AV. Vertebrate protein glycosylation: diversity, synthesis and function. Nat Rev Mol Cell Biol (2012) 13(7):448-62. doi:10.1038/nrm3383

4. Christiansen MN, Chik J, Lee L, Anugraham M, Abrahams JL, Packer NH. Cell surface protein glycosylation in cancer. Proteomics (2014) 14(4-5):525-46. doi:10.1002/pmic.201300387

5. Karsten U, Goletz S. What controls the expression of the core-1 (ThomsenFriedenreich) glycotope on tumor cells? Biochemistry (Mosc) (2015) 80(7):801-7. doi:10.1134/S0006297915070019

6. Ju TZ, Cummings RD, Canfield WM. Purification, characterization, and subunit structure of rat core 1 beta 1,3-galactosyltransferase. J Biol Chem (2002) 277(1):169-77. doi:10.1074/jbc.M109056200

7. Kannan S, Lakku RA, Niranjali D, Jayakumar K, Steven AH, Taralakshmi VV, et al. Expression of peanut agglutinin-binding mucin-type glycoprotein in human esophageal squamous cell carcinoma as a marker. Mol Cancer (2003) 2:38. doi:10.1186/1476-4598-2-38

8. Chacko BK, Appukuttan PS. Peanut (Arachis hypogaea) lectin recognizes alpha-linked galactose, but not $\mathrm{N}$-acetyl lactosamine in $\mathrm{N}$-linked oligosaccharide terminals. Int J Biol Macromol (2001) 28(5):365-71. doi:10.1016/ S0141-8130(01)00139-8

9. Baldus SE, Hanisch FG, Monaca E, Karsten UR, Zirbes TK, Thiele J, et al. Immunoreactivity of Thomsen-Friedenreich (TF) antigen in human

\section{CONCLUSION REMARKS}

The occurrence of the oncofetal TF antigen and the increased expression of galectins are both common features in cancer. More and more evidence has revealed that TF antigen is a natural ligand of galectins in cancer, and the galectin-TF interaction promotes a number of key steps (e.g., cancer cell heterotypic adhesion and homotypic aggregation) in the cancer progression and metastasis. Such a cancer-associated molecular interaction, as a result of highly specific occurrence of TF antigen in cancer cells, offers a potential therapeutic target for the development of novel strategies for cancer treatment. Moreover, as galectins are widely expressed by many types of human cells, cancer-associated TF may interact with galectins expressed by other cell types (e.g., immune cells) and influence cancer progression and metastasis. Further investigations in these areas are warranted. Structurally, more studies are needed to understand the galectin-TF interaction at atomic levels using full-length galectins.

\section{AUTHOR CONTRIBUTIONS}

All authors contributed to the preparation of the manuscript, and all read and approved the final version of the manuscript.

\section{FUNDING}

The work in the authors' laboratories was supported by grants from MRC, BBSRC, Cancer Research UK, and North West of Cancer Research Fund. PS was supported by an MRC Industrial Case Studentship.

neoplasms: the importance of carrier-specific glycotope expression on MUC1. Histol Histopathol (1999) 14(4):1153-8.

10. Wolf MF, Ludwig A, Fritz P, Schumacher K. Increased expression of ThomsenFriedenreich antigens during tumor progression in breast-cancer patients Tumor Biol (1988) 9(4):190-4. doi:10.1159/000217561

11. Baldus SE, Zirbes TK, Hanisch FG, Kunze D, Shafizadeh ST, Nolden S, et al. Thomsen-Friedenreich antigen presents as a prognostic factor in colorectal carcinoma - a clinicopathologic study of 264 patients. Cancer (2000) 88(7):1536-43. doi:10.1002/ (SICI) 1097-0142(20000401)88:7<1536::AID-CNCR6>3.0.CO;2-W

12. Takanami I. Expression of Thomsen-Friedenreich antigen as a marker of poor prognosis in pulmonary adenocarcinoma. Oncol Rep (1999) 6(2):341-4.

13. Ju TZ, Brewer K, D'Souza A, Cummings RD, Canfield WM. Cloning and expression of human core 1 beta 1,3-galactosyltransferase. J Biol Chem (2002) 277(1):178-86. doi:10.1074/jbc.M109060200

14. Beatson R, Maurstad G, Picco G, Arulappu A, Coleman J, Wandell HH, et al. The breast cancer-associated glycoforms of MUC1, MUC1-Tn and sialyl-Tn, are expressed in COSMC wild-type cells and bind the C-type lectin MGL. PLoS One (2015) 10(5):21. doi:10.1371/journal.pone.0125994

15. Yu LG. The oncofetal Thomsen-Friedenreich carbohydrate antigen in cancer progression. Glycoconj J (2007) 24(8):411-20. doi:10.1007/s10719-007-9034-3

16. Brockhausen I, Yang JM, Burchell J, Whitehouse C, Taylorpapadimitriou J. Mechanisms underlying aberrant glycosylation of mucl mucin in breast-cancer cells.EurJ Biochem(1995)233(2):607-17.doi:10.1111/j.1432-1033.1995.607_2.x

17. Whitehouse C, Burchell J, Gschmeissner S, Brockhausen I, Lloyd KO, TaylorPapadimitriou J. A transfected sialyltransferase that is elevated in breast cancer and localizes to the medial/trans-Golgi apparatus inhibits the development of core-2-based O-glycans. J Cell Biol (1997) 137(6):1229-41. doi:10.1083/jcb.137.6.1229 
18. Kuhns W, Jain RK, Matta KL, Paulsen H, Baker MA, Geyer R, et al. Characterization of a novel mucin sulfotransferase activity synthesizing sulfated o-glycan core 1,3-sulfate-gal-beta-1-3galnac-alpha-r. Glycobiology (1995) 5(7):689-97. doi:10.1093/glycob/5.7.689

19. Kumamoto K, Goto Y, Sekikawa K, Takenoshita S, Ishida N, Kawakita M, et al. Increased expression of UDP-galactose transporter messenger RNA in human colon cancer tissues and its implication in synthesis of ThomsenFriedenreich antigen and sialyl Lewis A/X determinants. Cancer Res (2001) 61(11):4620-7.

20. Rivinoja A, Kokkonen N, Kellokumpu I, Kellokumpu S. Elevated Golgi pH in breast and colorectal cancer cells correlates with the expression of oncofetal carbohydrate T-antigen. J Cell Physiol (2006) 208(1):167-74. doi:10.1002/ jcp.20653

21. Wang YC, Ju TZ, Ding XK, Xia BY, Wang WY, Xia LJ, et al. COSMC is an essential chaperone for correct protein O-glycosylation. Proc Natl Acad Sci U $S$ A (2010) 107(20):9228-33. doi:10.1073/pnas.0914004107

22. Ju TZ, Lanneau GS, Gautam T, Wang YC, Xia BY, Stowell SR, et al. Human tumor antigens to and sialyl Tn arise from mutations in Cosmc. Cancer Res (2008) 68(6):1636-46. doi:10.1158/0008-5472.CAN-07-2345

23. Hofmann BT, Schluter L, Lange P, Mercanoglu B, Ewald F, Folster A, et al. COSMC knockdown mediated aberrant O-glycosylation promotes oncogenic properties in pancreatic cancer. Mol Cancer (2015) 14:15. doi:10.1186/ s12943-015-0386-1

24. Huang J, Che MI, Lin NY, Hung JS, Huang YT, Lin WC, et al. The molecular chaperone Cosmc enhances malignant behaviors of colon cancer cells via activation of Akt and ERK. Mol Carcinog (2014) 53:E62-71. doi:10.1002/ mc. 22011

25. Singh R, Campbell BJ, Yu LG, Fernig DG, Milton JD, Goodlad R, et al. Cell surface-expressed Thomsen-Friedenreich antigen in colon cancer is predominantly carried on high molecular weight splice variants of CD44. Glycobiology (2001) 11(7):587-92. doi:10.1093/glycob/11.7.587

26. Cao Y, Merling A, Karsten U, Goletz S, Punzel M, Kraft R, et al. Expression of CD175 (Tn), CD175s (sialosyl-Tn) and CD176 (Thomsen-Friedenreich antigen) on malignant human hematopoietic cells. Int J Cancer (2008) 123(1):89-99. doi:10.1002/ijc.23493

27. Senapati S, Chaturvedi P, Chaney WG, Chakraborty S, Gnanapragassam VS, Sasson AR, et al. Novel interaction of MUC4 and galectin: potential pathobiological implications for metastasis in lethal pancreatic cancer. Clin Cancer Res (2011) 17(2):267-74. doi:10.1158/1078-0432.CCR-10-1937

28. Baldus SE, Hanisch FG, Kotlarek GM, Zirbes TK, Thiele J, Isenberg J, et al. Coexpression of MUC1 mucin peptide core and the Thomsen-Friedenreich antigen in colorectal neoplasms. Cancer (1998) 82(6):1019-27. doi:10.1002/ (SICI)1097-0142(19980315)82:6<1019::AID-CNCR3>3.0.CO;2-9

29. Karsten U, Goletz S. What makes cancer stem cell markers different? Springerplus (2013) 2:8. doi:10.1186/2193-1801-2-301

30. Krause DS, Fackler MJ, Civin CI, May WS. CD34: structure, biology, and clinical utility. Blood (1996) 87(1):1-13.

31. Zoller M.CD44: can a cancer-initiating cell profit from an abundantly expressed molecule? Nat Rev Cancer (2011) 11(4):254-67. doi:10.1038/nrc3023

32. Hilkens J, Ligtenberg MJL, Vos HL, Litvinov SV. Cell membrane-associated mucins and their adhesion-modulating property. Trends Biochem Sci (1992) 17(9):359-63. doi:10.1016/0968-0004(92)90315-Z

33. Lloyd KO, Burchell J, Kudryashov V, Yin BWT, TaylorPapadimitriou J. Comparison of O-linked carbohydrate chains in MUC-1 mucin from normal breast epithelial cell lines and breast carcinoma cell lines - demonstration of simpler and fewer glycan chains in tumor cells. J Biol Chem (1996) 271(52):33325-34. doi:10.1074/jbc.271.52.33325

34. Wesseling J, Vandervalk SW, Vos HL, Sonnenberg A, Hilkens J. Episialin (mucl) overexpression inhibits integrin-mediated cell-adhesion to extracellular-matrix components. J Cell Biol (1995) 129(1):255-65. doi:10.1083/ jcb.129.1.255

35. Barondes SH, Cooper DNW, Gitt MA, Leffler H. Galectins - structure and function of a large family of animal lectins. J Biol Chem (1994) 269(33):20807-10.

36. Klyosov AA, Witczak ZJ, Platt D. Galectins. Hoboken, NJ: Wiley (2008).

37. Nagae M, Nishi N, Murata T, Usui T, Nakamura T, Wakatsuki S, et al. Crystal structure of the galectin-9 N-terminal carbohydrate recognition domain from
Mus musculus reveals the basic mechanism of carbohydrate recognition. J Biol Chem (2006) 281(47):35884-93. doi:10.1074/jbc.M606648200

38. Massa SM, Cooper DNW, Leffler H, Barondes SH. L-29, an endogenous lectin, binds to glycoconjugate ligands with positive cooperativity. Biochemistry (1993) 32(1):260-7. doi:10.1021/bi00052a033

39. Ahmad N, Gabius HJ, Sabesan S, Oscarson S, Brewer CF. Thermodynamic binding studies of bivalent oligosaccharides to galectin-1, galectin-3, and the carbohydrate recognition domain of galectin-3. Glycobiology (2004) 14(9):817-25. doi:10.1093/glycob/cwh095

40. Hirabayashi J, Hashidate T, Arata Y, Nishi N, Nakamura T, Hirashima M, et al. Oligosaccharide specificity of galectins: a search by frontal affinity chromatography. Biochim Biophys Acta (2002) 1572(2-3):232-54. doi:10.1016/ S0304-4165(02)00311-2

41. Stowell SR, Arthur CM, Mehta P, Slanina KA, Blixt O, Leffler H, et al. Galectin-1,-2, and-3 exhibit differential recognition of sialylated glycans and blood group antigens. J Biol Chem (2008) 283(15):10109-23. doi:10.1074/jbc. M709545200

42. Kim HJ, Do IG, Jeon HK, Cho YJ, Park YA, Choi JJ, et al. Galectin 1 expression is associated with tumor invasion and metastasis in stage IB to IIA cervical cancer. Hum Pathol (2013) 44(1):62-8. doi:10.1016/j. humpath.2012.04.010

43. Chen J,Zhou SJ, Zhang Y,Zhang GQ,Zha TZ, Feng YZ, et al. Clinicopathological and prognostic significance of galectin-1 and vascular endothelial growth factor expression in gastric cancer. World J Gastroenterol (2013) 19(13):2073-9. doi:10.3748/wjg.v19.i13.2073

44. Liu FT, Rabinovich GA. Galectins as modulators of tumour progression. Nat Rev Cancer (2005) 5(1):29-41. doi:10.1038/nrc1527

45. Glinsky VV, Glinsky GV, Rittenhouse-Olson K, Huflejt ME, Glinskii OV, Deutscher SL, et al. The role of Thomsen-Friedenreich antigen in adhesion of human breast and prostate cancer cells to the endothelium. Cancer Res (2001) 61(12):4851-7.

46. Glinsky VV, Glinsky GV, Glinskii OV, Huxley VH, Turk JR, Mossine VV, et al. Intravascular metastatic cancer cell homotypic aggregation at the sites of primary attachment to the endothelium. Cancer Res (2003) 63(13):3805-11. doi:10.1016/j.urolonc.2003.12.009

47. Glinsky VV, Huflejt ME, Glinsky GV, Deutscher SL, Quinn TP. Effects of Thomsen-Friedenreich antigen-specific peptide P-30 on beta-galactosidemediated homotypic aggregation and adhesion to the endothelium of MDAMB-435 human breast carcinoma cells. Cancer Res (2000) 60(10):2584-8.

48. Heimburg J, Yan J, Morey S, Glinskii OV, Huxley VH, Wild L, et al. Inhibition of spontaneous breast cancer metastasis by anti-Thomsen-Friedenreich antigen monoclonal antibody JAA-F11. Neoplasia (2006) 8(11):939-48. doi:10.1593/neo.06493

49. Heimburg-Molinaro J, Almogren A, Morey S, Glinskii OV, Roy R, Wilding GE, et al. Development, characterization, and immunotherapeutic use of peptide mimics of the Thomsen-Friedenreich carbohydrate antigen. Neoplasia (2009) 11(8):780-92. doi:10.1593/neo.09504

50. Glinskii OV, Huxley VH, Glinsky GV, Pienta KJ, Raz A, Glinsky VV. Mechanical entrapment is insufficient and intercellular adhesion is essential for metastatic cell arrest in distant organs. Neoplasia (2005) 7(5):522-7. doi:10.1593/neo.04646

51. Glinskii OV, Turk JR, Pienta KJ, Huxley VH, Glinsky VV. Evidence of porcine and human endothelium activation by cancer-associated carbohydrates expressed on glycoproteins and tumour cells. J Physiol (2004) 554(1):89-99. doi:10.1113/jphysiol.2003.054783

52. Iurisci I, Tinari N, Natoli C, Angelucci D, Cianchetti E, Iacobelli S. Concentrations of galectin-3 in the sera of normal controls and cancer patients. Clin Cancer Res (2000) 6(4):1389-93.

53. Yu LG, Andrews N, Zhao Q, McKean D, Williams JF, Connor LJ, et al. Galectin-3 interaction with Thomsen-Friedenreich disaccharide on cancer-associated MUC1 causes increased cancer cell endothelial adhesion. J Biol Chem (2007) 282(1):773-81. doi:10.1074/jbc.M606862200

54. Zhao QC, Guo XL, Nash GB, Stone PC, Hilkens J, Rhodes JM, et al. Circulating galectin-3 promotes metastasis by modifying MUC1 localization on cancer cell surface. Cancer Res (2009) 69(17):6799-806. doi:10.1158/0008-5472. CAN-09-1096 
55. Zhao QC, Barclay M, Hilkens J, Guo XL, Barrow H, Rhodes JM, et al. Interaction between circulating galectin-3 and cancer-associated MUC1 enhances tumour cell homotypic aggregation and prevents anoikis. $\mathrm{Mol}$ Cancer (2010) 9:12. doi:10.1186/1476-4598-9-154

56. Aceto N, Bardia A, Miyamoto DT, Donaldson MC, Wittner BS, Spencer JA, et al. Circulating tumor cell clusters are oligoclonal precursors of breast cancer metastasis. Cell (2014) 158(5):1110-22. doi:10.1016/j.cell.2014.07.013

57. Barrow H, Guo XL, Wandall HH, Pedersen JW, Fu B, Zhao QC, et al. Serum galectin-2,-4, and -8 are greatly increased in colon and breast cancer patients and promote cancer cell adhesion to blood vascular endothelium. Clin Cancer Res (2011) 17(22):7035-46. doi:10.1158/1078-0432.CCR-11-1462

58. John CM, Leffler H, Kahl-Knutsson B, Svensson I, Jarvis GA. Truncated galectin-3 inhibits tumor growth and metastasis in orthotopic nude mouse model of human breast cancer. Clin Cancer Res (2003) 9(6):2374-83.

59. Oberg CT, Leffler H, Nilsson UJ. Arginine binding motifs: design and synthesis of galactose-derived arginine tweezers as galectin-3 inhibitors. J Med Chem (2008) 51(7):2297-301. doi:10.1021/jm701266y

60. Duckworth CA, Guimond SE, Sindrewicz P, Hughes AJ, French NS, Lian LY, et al. Chemically modified, non-anticoagulant heparin derivatives are potent galectin-3 binding inhibitors and inhibit circulating galectin-3-promoted metastasis. Oncotarget (2015) 6(27):23671-87. doi:10.18632/oncotarget.4409

61. Lobsanov YD, Gitt MA, Leffler H, Barondes SH, Rini JM. X-ray crystalstructure of the human dimeric s-lac lectin, 1-14-ii, in complex with lactose at 2.9-angstrom resolution. J Biol Chem (1993) 268(36):27034-8.

62. Seetharaman J, Kanigsberg A, Slaaby R, Leffler H, Barondes SH, Rini JM. $\mathrm{X}$-ray crystal structure of the human galectin-3 carbohydrate recognition domain at 2.1-angstrom resolution. J Biol Chem (1998) 273(21):13047-52. doi:10.1074/jbc.273.21.13047

63. Bian CF, Zhang Y, Sun H, Li DF, Wang DC. Structural basis for distinct binding properties of the human galectins to Thomsen-Friedenreich antigen. PLoS One (2011) 6(9):10. doi:10.1371/journal.pone.0025007

64. Morris S, Ahmad N, Andre S, Kaltner H, Gabius HJ, Brenowitz M, et al. Quaternary solution structures of galectins-1,-3, and-7. Glycobiology (2004) 14(3):293-300. doi:10.1093/glycob/cwh029

65. Walser PJ, Haebel PW, Kunzler M, Sargent D, Kues U, Aebi M, et al. Structure and functional analysis of the fungal galectin CGL2. Structure (2004) 12(4):689-702. doi:10.1016/j.str.2004.03.002

66. Feng L, Sun H, Zhang Y, Li DF, Wang DC. Structural insights into the recognition mechanism between an antitumor galectin AAL and the Thomsen-Friedenreich antigen. FASEB J (2010) 24(10):3861-8. doi:10.1096/ f. $10-159111$

67. Lin TW, Chang HT, Chen CH, Lin SW, Hsu TL, Wong CH. Galectin-3 binding protein and galectin-1 interaction in breast cancer cell aggregation and metastasis. J Am Chem Soc (2015) 137(30):9685-93. doi:10.1021/jacs.5b04744
68. Andre S, Maljaars CEP, Halkes KM, Gabius HJ, Kamerling JP. Discovery of galectin ligands in fully randomized combinatorial one-bead-one-compound (glyco)peptide libraries. Bioorg Med Chem Lett (2007) 17(3):793-8. doi:10.1016/j.bmcl.2006.10.067

69. Andre S, Giguere D, Dam TK, Brewer F, Gabius HJ, Roy R. Synthesis and screening of a small glycomimetic library for inhibitory activity on medically relevant galactoside-specific lectins in assays of increasing biorelevance. $\mathrm{New}$ J Chem (2010) 34(10):2229-40. doi:10.1039/c0nj00277a

70. Arai K, Tsutsumi H, Mihara H. A monosaccharide-modified peptide phage library for screening of ligands to carbohydrate-binding proteins. Bioorg Med Chem Lett (2013) 23(17):4940-3. doi:10.1016/j.bmcl.2013.06.059

71. Yongye AB, Calle L, Arda A, Jimenez-Barbero J, Andre S, Gabius HJ, et al. Molecular recognition of the Thomsen-Friedenreich antigen-threonine conjugate by adhesion/growth regulatory galectin-3: nuclear magnetic resonance studies and molecular dynamics simulations. Biochemistry (2012) 51(37):7278-89. doi:10.1021/bi300761s

72. Rodriguez MC, Yegorova S, Pitteloud JP, Chavaroche AE, Andre S, Arda A, et al. Thermodynamic switch in binding of adhesion/growth regulatory human galectin-3 to tumor-associated TF antigen (CD176) and MUC1 glycopeptides. Biochemistry (2015) 54(29):4462-74. doi:10.1021/acs. biochem.5b00555

73. Weis WI, Drickamer K. Structural basis of lectin-carbohydrate recognition. Annu Rev Biochem (1996) 65:441-73. doi:10.1146/annurev. bi.65.070196.002301

74. Lis H, Sharon N. Lectins: carbohydrate-specific proteins that mediate cellular recognition. Chem Rev (1998) 98(2):637-74. doi:10.1021/cr940413g

75. Dam TK, Gabius HJ, Andre S, Kaltner H, Lensch M, Brewer CF. Galectins bind to the multivalent glycoprotein asialofetuin with enhanced affinities and a gradient of decreasing binding constants. Biochemistry (2005) 44(37):12564-71. doi:10.1021/bi051144z

76. Hsieh TJ, Lin HY, Tu ZJ, Huang BS, Wu SC, Lin CH. Structural basis underlying the binding preference of human galectins-1,-3 and-7 for Gal beta 1-3/4GlcNAc. PLoS One (2015) 10(5):19. doi:10.1371/journal.pone.0125946

Conflict of Interest Statement: The authors declare that the research was conducted in the absence of any commercial or financial relationships that could be construed as a potential conflict of interest.

Copyright ( $(2016$ Sindrewicz, Lian and Yu. This is an open-access article distributed under the terms of the Creative Commons Attribution License (CC BY). The use, distribution or reproduction in other forums is permitted, provided the original author(s) or licensor are credited and that the original publication in this journal is cited, in accordance with accepted academic practice. No use, distribution or reproduction is permitted which does not comply with these terms. 